\title{
Mutual Fund Trading and Portfolio Disclosures
}

\section{Cristina Ortiz, Gloria Ramírez \& Luis Vicente}

Journal of Financial Services

Research

ISSN 0920-8550

J Financ Serv Res

DOI 10.1007/s10693-014-0198-2

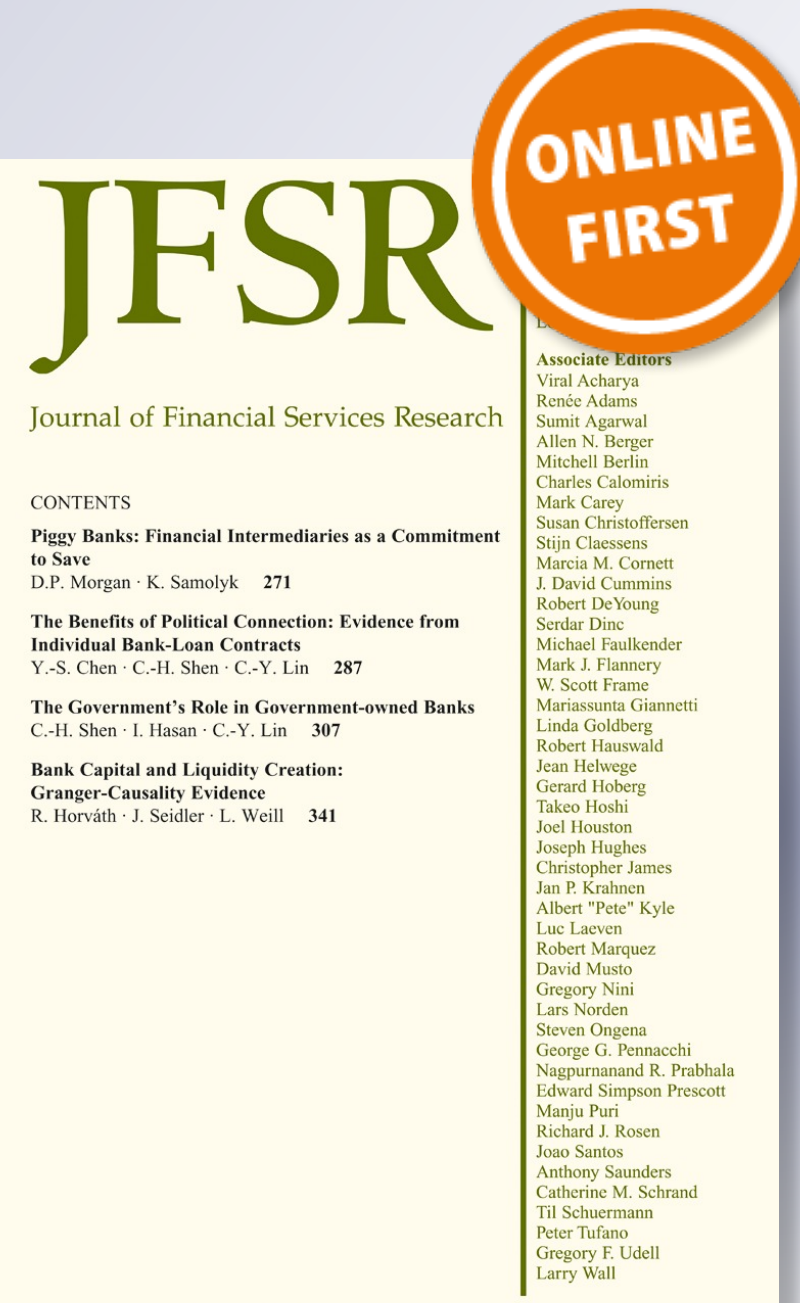

Vol. 45, No. 3, June 2014

를 Springer 
Your article is protected by copyright and all rights are held exclusively by Springer Science +Business Media New York. This e-offprint is for personal use only and shall not be selfarchived in electronic repositories. If you wish to self-archive your article, please use the accepted manuscript version for posting on your own website. You may further deposit the accepted manuscript version in any repository, provided it is only made publicly available 12 months after official publication or later and provided acknowledgement is given to the original source of publication and a link is inserted to the published article on Springer's website. The link must be accompanied by the following text: "The final publication is available at link.springer.com". 


\title{
Mutual Fund Trading and Portfolio Disclosures
}

\author{
Cristina Ortiz • Gloria Ramírez • Luis Vicente
}

Received: 27 September 2012 / Revised: 15 May 2014 / Accepted: 13 June 2014

(C) Springer Science+Business Media New York 2014

\begin{abstract}
This is the first study in a large European market which analyzes monthly portfolios to obtain evidence of equity fund trading around quarterly reports. A new portfolio-weight approach shows that managers disclose large-cap and well-known stocks with higher returns and hide the same return-loser stocks in the reporting months. A fund-size agency problem plays an important role in this window dressing evidence. Fund trading also shows that managers benefits from the January effect by buying small-cap stocks at the beginning of the year rather than causing this anomaly.
\end{abstract}

Keywords Mutual funds · Window dressing · January effect · Agency problem ·

Intra-quarter trading

JEL Classification $\mathrm{G} 11 \cdot \mathrm{G} 12 \cdot \mathrm{G} 23$

\section{Introduction}

Mutual fund trading in disguise and their consequences are a challenging topic in the financial literature since the paper of Lakonishok et al. (1991). The potential portfolio manipulation around disclosures may reveal an uninformative image of the recent management of the fund. This phenomenon is broadly known as window dressing. Some other papers devoted to study window dressing in the U.S. equity fund market are $\mathrm{He}$ et al. (2004) and $\mathrm{Ng}$ and Wang (2004). ${ }^{1}$

The above-cited papers document evidence of window dressing analyzing quarterly portfolios. However, in a recent work, Elton et al. (2010) show that low portfolio data frequency

\footnotetext{
${ }^{1}$ This window dressing phenomenon has also been tested for other financial institutions i.e. for the balance sheet activity in banks (Kotomin and Winters, 2006).

C. Ortiz $(\bowtie) \cdot$ L. Vicente

Department of Accounting and Finance, Universidad de Zaragoza, C/Gran Vía 2, 50.005, Zaragoza, Spain e-mail: cortiz@unizar.es

L. Vicente

e-mail: lavicent@unizar.es

G. Ramírez

Department of Industrial Engineering, Universidad de Antioquia, C/67 \# 53-108, Medellín, Colombia e-mail: glraco@gmail.com
} 
(e.g., semi-annual or even quarterly data) may provide misleading evidence regarding mutual fund behavior because the trades between disclosed portfolio reports (intra-period round-trip trades) cannot be observed, and because the estimated timing of a trade is imprecise. Higher frequencies are necessary to obtain accurate conclusions concerning mutual fund trading. Some recent studies address this problem by conducting tests of some well-known hypotheses in the U.S. mutual-fund industry. Elton et al. (2012) use monthly holdings to study market timing ability, and Liao et al. (2010) analyze monthly portfolios to test herding behavior. Regarding studies on window dressing with lower frequency than quarterly, we can only report analyses of bond fund portfolios, the studies of Musto (1999) in the U.S. and Ortiz et al. (2012) in Spain. This paper intends to fill this gap in the literature and analyzes monthly trades in Spanish equity funds.

Nonetheless, besides the frequency of the data, the key element to draw conclusions on true window dressing is whether portfolios are disclosed or undisclosed. Specifically, Musto (1999) was the first study that clearly stated that the test of window dressing requires the use of disclosed and undisclosed portfolios. Unlike in other well-known markets, managers in Spain must report to investors on a quarterly basis, which is more frequent than the European Union's requirement of semi-annual portfolio reports. ${ }^{2}$ However, even more relevant, the Spanish regulator collects monthly portfolios. This study benefits from this unique and official database of undisclosed reports to offer new insights into mutual fund trading in Spain. In fact, the use of quarterly data misses $38 \%$ of the trades estimated using monthly data.

The immediate question for investors to evaluate the validity of disclosed portfolios is whether the intra-quarter trading entails differential returns for the fund; that is, to test whether the trading in disguise significantly affects fund returns. The unobserved trading of managers can be creating value for the portfolio but it hides transaction costs at the same time. Our results show that there is no differential return in calculating hypothetical returns with disclosed or undisclosed portfolios. This result is in line with Kacperczyk et al. (2008) that show that the magnitude of unobserved actions is relatively small in the aggregate for a sample of U.S. equity funds.

The application of $\mathrm{Ng}$ and Wang's (2004) ratios in monthly holdings allows us to better identify the characteristics of the stocks that managers buy and sell more intensively each period. This study also contributes to the literature proposing a complementary methodological approach that analyzes the changes in the portfolio weights as a whole, thereby capturing the overall effect of the fund trading on the portfolio image.

As far as we know, this is the first analysis of undisclosed monthly portfolios of a sample of equity funds in the European industry. The analysis of an industry different to the U.S. is needed also for equity funds, indeed the conclusions of the paper of Ortiz et al. (2012) differ from the U.S. market (Musto 1999) for bond funds because government bonds are not so desirable in disclosed portfolios in Spain as in the U.S.

Our empirical analysis is based on the detection of window dressing. We investigate whether the existence of investment strategies in disguise between quarterly reports result in trading patterns around the reporting dates that significantly differ from the usual management practices in the rest of the year (Lakonishok et al. 1991). This is possible using a monthly undisclosed database. A detailed analysis of the timing and magnitude of these trades should show whether the portfolios disclosed on a quarterly basis reveal meaningful information to investors. The results show that managers tend to rebalance

\footnotetext{
${ }^{2}$ European Council Directive 2001/107/EC of 21 January 2002 partially amends Directive 85/611/EEC of 20 December 1985 on the coordination of laws, regulations and administrative provisions relating to Undertakings for Collective Investment in Transferable Securities (UCITS).
} 
their portfolios to disclose well-known stocks in their quarterly reports. In addition to this finding, managers tend to buy and increase the portfolio weights of the smallest-cap stocks in the remaining months. A more detailed analysis provides evidence that a fundsize agency problem may drive this practice.

This paper also investigates whether window dressing practices affect funds' returns. Managers may have incentives to obtain total returns to benefit from the convex performance-flow relationship and attract larger flows of money. Several tests seem to show that any good strategy in intra-quarter periods do not compensate trading costs and do not lead to superior returns.

Furthermore, we relate our results with another well-known investing strategy analyzed in the literature, such as the January effect. There is extensive research on the participation of mutual funds in this January return anomaly (e.g. Haugen and Lakonishok (1988), Lee et al. (1998), Musto (1997), and Sias and Starks (1997), among others) but the role of fund managers remains a compelling question in the literature. However, unlike the U.S. mutual funds, Spanish funds own a low share of the Spanish stock capitalization. Our results show that the abnormally high buying activity of small-cap stocks in January probably means a trading pattern to benefit from the January effect rather than creating this return anomaly.

The rest of the paper proceeds as follows. Section two describes the database and explores the intra-quarter round-trip missing trades. Section three examines whether mutual funds manage differently their portfolios around disclosures, the effect on the fund returns and the relation with other variables such as size or past return. Section four investigates the role of fund managers in a well-known investing pattern as the January effect is. This paper ends with the main conclusions of the research.

\section{Data and Intra-Quarter Trades}

\subsection{Data}

The database used in this paper consists of monthly portfolio reports of all Spanish domestic equity funds from December 1999 to December 2006. ${ }^{3}$ The regulator, the Spanish Securities Exchange Commission (CNMV) supplied us with the database. The data are free of the well-known survivorship and look-ahead biases. The initial sample includes 163 funds that report at least one year of monthly holdings. From this sample we eliminate funds that do not meet the main official investment requirement of this category; that is, funds which held less than $75 \%$ of their assets in Spanish stock exchange in any month in order to ensure that all portfolios analyzed were appropriately classified as Spanish domestic equity funds. The final database consists of 125 Spanish domestic equity funds and 7,032 fund months, with an average of 56 monthly reports per fund and at least 91 funds each month. About $90 \%$ of the assets under management of domestic equity funds is controlled in the sample.

\footnotetext{
${ }^{3}$ According to the Spanish Collective Investment and Pension Funds Association (INVERCO), the number of Spanish domestic equity funds stood at 122 out of 2,794 existing in the Spanish mutual fund industry at the end of 2006, which represents about 5\% of assets under management of the overall market. Despite this low fraction, it is important to note that this domestic category is the most active participant of the fund industry in the Spanish stock exchange markets, holding more than $50 \%$ of the total assets invested by mutual funds in Spanish stocks. This result explains the relevance of this fund category to analyze mutual fund trading. Detailed statistics are available upon request.
} 
The CNMV provides this monthly information, thereby overcoming the problem of reporting selection bias, which may be present in the scarce research on high frequency portfolios where mutual funds voluntarily supply their reports to private data providers (Elton et al. 2010; Liao et al. 2010). Our database is not available to retail and institutional investors, and CNMV provides this information exclusively to the authors for research purposes. ${ }^{4}$ Therefore, managers could not anticipate the release of these undisclosed intra-quarter portfolios. The characteristics of our database are greatly adequate for the precepts of Musto (1999) who highlights the need of having disclosed and undisclosed portfolios to analyze window dressing.

The present study carefully identifies all of the portfolio holdings through the International Securities Identification Numbering (ISIN) codes. Panel A of Table 1 shows the portfolio composition of domestic stocks in the sample. The classification procedure begins by classifying the stocks traded on the last day of each quarter into two groups: the stocks belonging to the Spanish benchmark Ibex-35 (Ibex) and the other stocks (Nolbex). Then the procedure sorts the stocks within each initial group into two subgroups according to market capitalization: large and small. The large subgroup represents approximately $60 \%$ of the total group's market capitalization, and the small subgroup contains the remaining $40 \%$. Thus, the procedure obtains four groups: Ibex_Large, Ibex_Small, NoIbex_Large, and NoIbex_Small. ${ }^{5}$

Note that the funds show a strong preference for large and well-known Spanish stocks, as nearly $90 \%$ of the domestic portfolio sample belongs to Ibex-35 (Ibex_Large and Ibex_Small). Despite the low portfolio weights of Nolbex stocks, a comprehensive study must analyze these securities to obtain accurate evidence regarding the overall trading activities in the Spanish equity funds and their impact on the price patterns of the market. In addition, the increase in the portfolio weights of the smallest cap stocks (Nolbex_Small) is also remarkable, as these percentages tripled from December 1999 to December $2006{ }^{6}$

According to Table 1 (Panel B), the aggregate portfolio holds every stock listed in Ibex- 35 . These aggregate holdings also contain, on average, $90 \%$ and $75 \%$ of Nolbex_Large and NoIbex_Small stocks, respectively. However, in terms of market capitalization, these figures show the rather limited role of domestic equity funds in the Spanish stock market, as these funds own less than $2 \%$ of the total value of each stock group. ${ }^{7}$

\footnotetext{
${ }^{4}$ One may think why mutual fund managers disclose the monthly tape of their potential manipulation if they are aware that these reports will be probed by CNMV, and scrutinized by researchers. There are two main arguments that approve the validity of the database. First, as far as we know, the use of this information was unique and exclusive for the authors of this paper. Further applications to update this confidential information were rejected by the regulator, which questions whether managers might be aware of potential data analyses. Second, the systematic intra-month portfolio manipulation could involve important and additional transaction costs for equity funds in the case of removing any window dressing evidence from monthly disclosures.

${ }^{5}$ The remaining holdings average less than $25 \%$ of the portfolio sample and contain a wide range of foreign stocks, investment societies, and other mutual fund units. The study does not analyze these assets because of both the assorted nature of them, and the residual impact on the investment goal of domestic equity funds, which is focused on Spanish common stocks.

${ }^{6}$ There are not significant differences in the percentages displayed by Table 1 between quarter-end portfolios vs. other month-end portfolios. Detailed information is available upon request.

${ }^{7}$ This low percentage might suggest that other Spanish fund categories could largely increase this figure. However, according to additional statistics that are not reported in this study, the Spanish fund industry owns about $7 \%$ of the Spanish stock capitalization (December 2006).
} 
Table 1 Portfolio characteristics of Spanish domestic equity funds. This table reports the portfolio characteristics of the fund sample. Panel A displays the portfolio composition of the domestic stocks after the classification into four size groups (Ibex_Large, Ibex_Small, Nolbex_Large, and Nolbex_Small). This classification sorts the stocks into two groups: those that belong to the Spanish benchmark Ibex-35 (Ibex) and the remaining (NoIbex). Next, the procedure divides each group into large-cap stocks (Large) and small-cap stocks (Small). The Large subgroup represents approximately $60 \%$ of the total group's market capitalization. Panel B divides the stocks by size groups and shows the proportion of listed stocks held by the sample (\% Held) and the fraction of the Spanish stock market capitalization owned by the sample (\% Owned). These figures correspond to the last day of December in each year

\begin{tabular}{|c|c|c|c|c|c|c|c|c|}
\hline & 1999 & 2000 & 2001 & 2002 & 2003 & 2004 & 2005 & 2006 \\
\hline \multicolumn{9}{|c|}{ Panel A: Portfolio composition of domestic stocks } \\
\hline Ibex_Large & $46.8 \%$ & $51.2 \%$ & $40.4 \%$ & $35.0 \%$ & $39.9 \%$ & $35.2 \%$ & $32.6 \%$ & $35.6 \%$ \\
\hline Ibex_Small & $41.1 \%$ & $41.2 \%$ & $52.2 \%$ & $54.0 \%$ & $48.7 \%$ & $48.4 \%$ & $49.6 \%$ & $45.5 \%$ \\
\hline NoIbex_Large & $5.6 \%$ & $3.8 \%$ & $1.8 \%$ & $4.1 \%$ & $2.7 \%$ & $4.4 \%$ & $4.8 \%$ & $2.7 \%$ \\
\hline NoIbex_Small & $6.6 \%$ & $3.9 \%$ & $5.5 \%$ & $7.0 \%$ & $8.8 \%$ & $12.0 \%$ & $12.9 \%$ & $16.2 \%$ \\
\hline \multicolumn{9}{|c|}{ Panel B: Stock distribution } \\
\hline \multicolumn{9}{|l|}{ Ibex_Large } \\
\hline$\%$ Held & $100.0 \%$ & $100.0 \%$ & $100.0 \%$ & $100.0 \%$ & $100.0 \%$ & $100.0 \%$ & $100.0 \%$ & $100.0 \%$ \\
\hline$\%$ Owned & $1.0 \%$ & $0.8 \%$ & $0.6 \%$ & $0.6 \%$ & $0.7 \%$ & $0.7 \%$ & $0.8 \%$ & $0.8 \%$ \\
\hline \multicolumn{9}{|l|}{ Ibex_Small } \\
\hline$\%$ Held & $100.0 \%$ & $100.0 \%$ & $100.0 \%$ & $100.0 \%$ & $100.0 \%$ & $100.0 \%$ & $100.0 \%$ & $100.0 \%$ \\
\hline$\%$ Owned & $1.9 \%$ & $1.5 \%$ & $1.3 \%$ & $1.2 \%$ & $1.2 \%$ & $1.4 \%$ & $1.4 \%$ & $1.1 \%$ \\
\hline \multicolumn{9}{|l|}{ NoIbex_Large } \\
\hline$\%$ Held & $91.7 \%$ & $83.3 \%$ & $66.7 \%$ & $91.7 \%$ & $91.7 \%$ & $91.7 \%$ & $100.0 \%$ & $75.0 \%$ \\
\hline$\%$ Owned & $0.4 \%$ & $0.2 \%$ & $0.2 \%$ & $0.3 \%$ & $0.2 \%$ & $0.6 \%$ & $0.6 \%$ & $0.3 \%$ \\
\hline \multicolumn{9}{|l|}{ NoIbex_Small } \\
\hline$\%$ Held & $76.6 \%$ & $76.6 \%$ & $71.4 \%$ & $59.8 \%$ & $73.5 \%$ & $80.5 \%$ & $76.6 \%$ & $74.7 \%$ \\
\hline$\%$ Owned & $1.2 \%$ & $0.6 \%$ & $0.7 \%$ & $0.6 \%$ & $1.0 \%$ & $1.8 \%$ & $2.1 \%$ & $1.6 \%$ \\
\hline
\end{tabular}

\subsection{The Impact of Intra-Quarter Trades}

To highlight the importance of using monthly information rather than quarterly data, this study examines the number of missing trades that result from using quarterly portfolio reports. According to Elton et al. (2010), the procedure for computing the portfolio turnover in month $\mathrm{j}$ is:

$$
\begin{gathered}
C_{j}^{+}=\sum_{i}\left(N_{i j}-N_{i j-1}\right) \bar{P}_{i j} \text { for all } i, \text { where }\left(N_{i j}-N_{i j-1}\right) \geq 0 \\
C_{j}^{-}=\sum_{i}\left(N_{i j}-N_{i j-1}\right) \bar{P}_{i j} \text { for all } i, \text { where }\left(N_{i j}-N_{i j-1}\right)<0
\end{gathered}
$$

where $\mathrm{N}_{\mathrm{ij}}$ is the number of shares of stock $\mathrm{i}$ held at the end of month $\mathrm{j}$, and $\bar{P}_{i j}$ is the average of stock i's prices at the beginning and the end of month $\mathrm{j}$.

The annual turnover is the smaller of either purchases $(\mathrm{C}+)$ or sales $\left(\mathrm{C}^{-}\right)$divided by the average of the portfolio's net asset value over the previous year, where:

$$
C^{+}=\sum_{j=1}^{12} C_{j}^{+}
$$




$$
C^{-}=\sum_{j=1}^{12} C_{j}^{-}
$$

To obtain the annual turnover using quarterly portfolios, the estimation of Eq. (3) and (4) uses four quarterly changes in the holdings, instead of 12 monthly variations.

The annual turnover in the sample based on the monthly data is $51 \%$, whereas the annual turnover for the quarterly portfolios is $32 \%$. These results indicate that the use of quarterly data discards $38 \%$ of the trading observations from the monthly data. This finding supports the evidence that monthly portfolios significantly reduce the impact of intra-quarter round-trip trades on the empirical analyses of mutual fund trading (Elton et al. 2010).

To further understand the relevance of these intra-quarter trades, this study aims to disentangle the impact on fund returns of these missing trades between reporting schedules which are not directly observed when looking at the quarterly holding reports. According to Kacperczyk et al. (2008), we obtain the hypothetical monthly returns from quarterly holding reports (HMR_QR) and the hypothetical monthly returns from monthly holding reports (HMR_MR). The daily return of the fund k's holdings for each trading day $\mathrm{t}(\mathrm{RHk}, \mathrm{t})$ is computed as the total return of a hypothetical buy-and-hold strategy which invests in the most recent portfolio holdings report:

$$
R H_{k, t}=\sum_{i=1}^{j} \omega_{i, t-1} R_{i, t}
$$

where $\omega_{i, t-1}$ is the portfolio weight of asset $i$ on day $t-1 ; R_{i, t}$ is the return of asset $i$ on day $\mathrm{t}$; and $\mathrm{j}$ is the total number of assets in the portfolio.

Each report shows the assets invested the last day of the period $(t=0)$. However, the portfolio weights are only valid on the corresponding reporting day. It is necessary to estimate the daily portfolio weights for the subsequent days. As this estimation is performed under the assumption of a buy-and-hold strategy, it is necessary the daily updating of the portfolio weights according to the returns on all the assets included in the most recent portfolio report. ${ }^{8}$

From the daily RH obtained with disclosed quarterly reports, we estimate the hypothetical monthly returns obtained by the fund over the next 3 months (HMR_QR). Similarly, the hypothetical monthly returns over the next month (HMR_MR) are based on undisclosed monthly reports. We end up with 4,555 hypothetical monthly return observations. The average HMR_MR $(0.34 \%)$ is higher than the average HMR_QR $(0.32 \%)$, but this difference is not statistically significant ( $\mathrm{p}$-value $=0.67$ ). This finding suggests that the intra-quarter round trip trades of Spanish domestic equity funds have not a significant impact on fund returns.

\footnotetext{
${ }^{8}$ These daily asset returns are calculated from different datasets of daily closing prices. These returns are adjusted by dividends, stock splits and seasoned equity offerings. Spanish stock data are obtained from the Madrid Stock Exchange and European stock data are provided by Reuters DataLink. Fixed-income daily returns are provided by Analistas Financieros Internacionales (AFI). Finally, a low percentage of fund total assets (about 3\%) are noncontrolled securities, which together with cash and cash equivalents receive a zero return.
} 


\section{Empirical Analysis}

\subsection{Mutual Funds Trading and Portfolio Reports}

Mutual fund trading at the end of the performance reporting periods attracts considerable attention within the empirical literature. If managers plan their investment decisions according to the fund reporting schedule, the disclosed portfolios may reveal an uninformative image of the recent management of the fund. According to the straightforward approach of Musto (1999), empirical analyses must test the differences between the investment decisions made around the reporting dates and the decisions made throughout the rest of the year to determine whether managers intentionally manipulate the portfolios around the public reports.

Window-dressing practices may imply that higher levels of trading occur prior to reporting dates (Elton et al. 2010; Meier and Schaumburg 2006). Therefore, it is necessary to explore the intensity of mutual fund trading throughout the calendar year, and to search for abnormal trading patterns around the quarterly disclosures.

Following this first approach to window dressing, Table 2 reports the aggregate turnover ratios (Eqs. 1 to 4 ) for each month, quarter, and half-year. Trading activity is significantly higher $(6.40 \%)$ during the first half of the year than in the second half. In fact, managers engage in abnormally high trading just before the reporting dates in the first half of the year (March, $41.31 \%$; June, $39.58 \%$ ).

While paying special attention to the year-end, the findings show that the turnover in December $(30.81 \%)$ is the smallest in the year, with the only exception being the August turnover $(24.09 \%)$. This low turnover reflects the dampening effect of the summer holidays on fund management.

Although previous evidence on portfolio manipulation in the U.S. fund market is especially relevant at the end of the year (Lakonishok et al. 1991; Ng and Wang 2004; Elton et al. 2010; He et al. 2004), the lack of evidence for significant trading in December might imply that Spanish managers do not actively manipulate their portfolios in this month. Unlike the U.S. fund industry, Spanish funds all have the same fiscal year-end: December, and the low turnover in December also suggests that mutual funds do not engage in tax-motivated trading. This assumption gains strength because under Spanish tax law (Law 43/1995, of December 27, and the Royal Decree 4/2004, of March 5), mutual funds are not entitled to any tax deductions and benefit from a small corporate tax rate $(1 \%)$, which reduces tax-motivated trades around the end of the year. Hence, Spanish mutual funds do not appear to have a motivation to engage in tax-motivated trading at year-end.

But the analysis of window dressing hypothesis should further analyze the management activity displayed by the portfolio turnover. Therefore, it is necessary to identify the characteristics of the stocks that funds sell, buy, and hold each month to test whether managers trade in disguise around the disclosure dates. The first step consists in sorting the domestic stocks by their cumulative returns over the previous 11 months. These return records complement the four stock groups according to market capitalization (i.e., Ibex_Large, Ibex_Small, NoIbex_Large, and NoIbex_Small).

To evaluate the potential interaction between size and performance, the next stage obtains the 11-month return quartiles within each size group, that is, 16 performance-size subgroups. However, to obtain clearer results, this study only analyzes the extreme quartiles (i.e., Winners and Losers), which should be the most susceptible to portfolio manipulation. This classification provides eight equally-weighted subgroups: Ibex_LargeW, Ibex_LargeL, Ibex_SmallW, Ibex_SmallL, NoIbex_LargeW, NoIbex_LargeL, NoIbex_SmallW, and NoIbex_SmallL. These subgroups are rebalanced each quarter. 


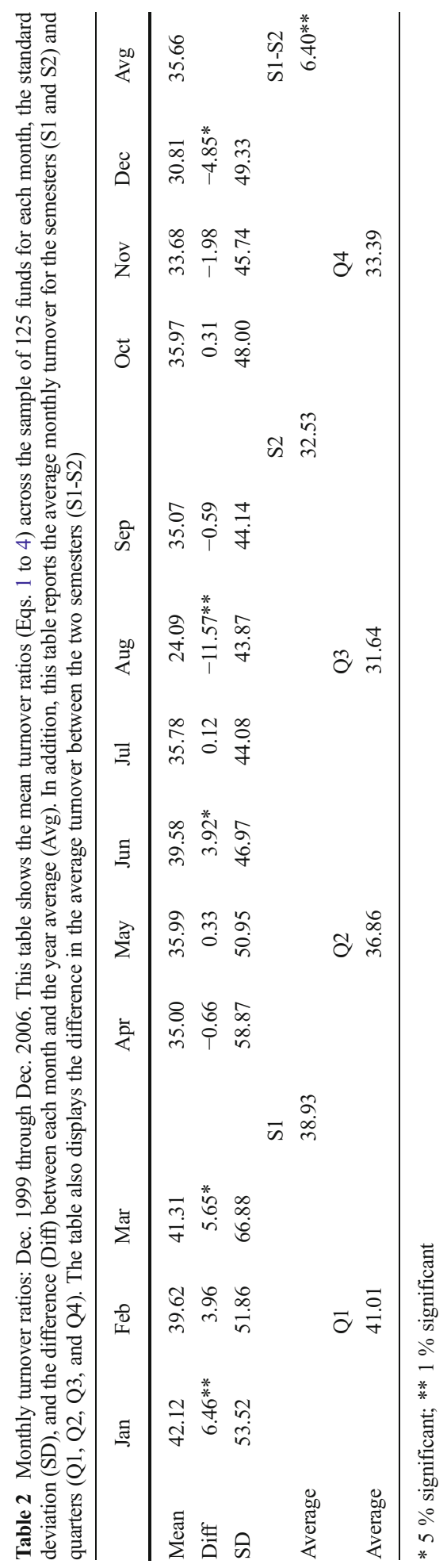


This study follows the approach of $\mathrm{Ng}$ and Wang (2004) to identify the stocks that managers buy and sell more intensively around the disclosure schedule. This method computes the value of the monthly holdings, sales, and purchases of each stock group for each mutual fund.

The sell ratio measures fund k's selling activities in stock group $\mathrm{i}$ in month $\mathrm{j}$ :

$$
\text { Sell ratio }=\frac{\operatorname{SELL}(i, j, k) / \operatorname{HOLD}(i, j-1, k)}{\sum_{i} \operatorname{SELL}(i, j, k) / \sum_{i} \operatorname{HOLD}\left(i, j^{-1, k)}\right.}
$$

where $\operatorname{SELL}(i, j, k)$ are the fund k's sales in month $\mathrm{j}$ and in stock group $\mathrm{i}$, and $\operatorname{HOLD}(\mathrm{i}, \mathrm{j}-1, \mathrm{k})$ is the value of the holdings at the end of the previous month of the same stock group $i$ in month j. The values of SELL and HOLD use the average stock prices between the beginning and end of month $\mathrm{j}$.

The numerator in Eq. 6 is the ratio of the sales in stock group $i$ to the holdings of the same group $i$ at the end of the previous month, while the denominator is the ratio of the total sales of all stock groups in month $\mathrm{j}$ to all stock holdings at the end of the previous month. That is, the sell ratio measures the selling activity of the fund in a given stock group relative to the overall selling activity of the fund in month $\mathrm{j}$. Suppose that a manager sells $600,000 €$ out of $1,000,000$ $€$ held in Ibex_Large stocks. In addition, this manager sells $150,000 €$ out of $700,000 €$ held in Ibex_Small stocks, 40,000€ out of 200,000€ held in Nolbex_Large stocks, and 10,000€ out of $100,000 €$ held in NoIbex_Small stocks. Therefore, according to Eq. 6 , the manager sells $60 \%$ of the Ibex_Large group held in the portfolio but only sells $40 \%$ of the total stock holdings. That is, the sell ratio for the Ibex_Large group is 1.5, which means that this fund sells $50 \%$ more of Ibex_Large than the overall selling activity.

Similarly, the buy ratio measures fund k's buying activities in stock group i in month $\mathrm{j}$ :

$$
\text { Buy ratio }=\frac{B U Y(i, j, k) / \operatorname{HOLD}(i, j, k)}{\sum_{i} B U Y(i, j, k) / \sum_{i} \operatorname{HOLD}(i, j, k)}
$$

where BUY $(\mathrm{i}, \mathrm{j}, \mathrm{k})$ are the fund k's purchases in month $\mathrm{j}$ in stock group $\mathrm{i}$, and $\operatorname{HOLD}(\mathrm{i}, \mathrm{j}, \mathrm{k})$ is the value of fund k's holdings in month $\mathrm{j}$ in stock group i. Again, the BUY and HOLD variables use the average of the stock prices at the beginning and end of month $\mathrm{j}$. Therefore, the buy ratio shows the proportion of the fund's purchases of stock group i during month $\mathrm{j}$ relative to the proportion of the fund's total purchases across all stock groups.

To complement the aforementioned measures of trading intensity, this study proposes a new complementary approach that allows the identification of the intensity of the changes in the portfolio allocations to the different stock groups. The importance of this method lies in the additional information reported because this measure compares the trading patterns of the different stock groups with the trading patterns of the entire portfolio. Whereas $\mathrm{Ng}$ and Wang (2004) analyze the buying/selling activity of funds, this approach explores the changes in the final portfolio weights that funds report to unit-holders. This new insight captures the overall effect on the stock weights disclosed to investors, which mainly determine the portfolio image.

The portfolio share decrease/increase ratios by fund $\mathrm{k}$ in stock group $\mathrm{i}$ during month j:

$$
\text { Share decrease }=\frac{[\operatorname{SHARE}(i, j, k)-\operatorname{SHARE}(i, j-1, k)]^{-}}{\operatorname{AVERAGE} E_{i}[\operatorname{SHARE}(i, j, k)-\operatorname{SHARE}(i, j-1, k)]^{-}}
$$




$$
\text { Share increase }=\frac{[\operatorname{SHARE}(i, j, k)-\operatorname{SHARE}(i, j-1, k)]^{+}}{\operatorname{AVERAGE}[\operatorname{SHARE}(i, j, k)-\operatorname{SHARE}(i, j-1, k)]^{+}}
$$

where $\operatorname{SHARE}(\mathrm{i}, \mathrm{j}, \mathrm{k})$ is the percentage of the portfolio invested by fund $\mathrm{k}$ in stock group $\mathrm{i}$ in month j. Equation 8 is valid for $\operatorname{SHARE}(i, j, k)-\operatorname{SHARE}(i, j-1, k)]<0$. Similarly, Eq. 9 applies if the difference [SHARE(i, j, k) - $\operatorname{SHARE}(\mathrm{i}, \mathrm{j}-1, \mathrm{k})]$ is positive.

With respect to the share increases, the numerator in Eq. 9 shows the increase in the portfolio share of stock group $\mathrm{i}$ in month $\mathrm{j}$ over the share in the previous month. The denominator is the average of the increases in all of the stock groups during month $\mathrm{j}$. Therefore, this ratio compares the increase intensity of stock group $i$ during month $j$ with respect to the average increments in fund k's portfolio allocations. Suppose a fund that holds $10 \%, 60 \%, 30 \%$, and $0 \%$ of its portfolio in Ibex_Large, Ibex_Small, NoIbex_Large, and NoIbex_Small stocks, respectively, in month j-1. The same fund holds $40 \%, 15 \%, 35 \%$, and $10 \%$, respectively, in month $\mathrm{j}$. That is, the fund has increased $30 \%$ of its portfolio allocation to the Ibex_Large group, but the average increment in the portfolio weights is $15 \%$ (i.e. $30 \%$ of Ibex_Large stocks, $5 \%$ of Nolbex_Large stocks, and $10 \%$ of NoIbex_Small stocks). The share increase ratio for Ibex_Large stocks is 2.0, which means that this fund increases its portfolio allocations to these stocks at twice the average increments of the remaining allocations. In this case, the share decrease ratio (Eq. 8) for Ibex_Small stocks is 1.0, given that it is the only underweighting of stocks in month $\mathrm{j}$.

This study uses both trading activity and portfolio allocation measures to test whether trading differs between the disclosure months (March, June, September, and December), which are denoted hereafter as Qs, and the other eight months, which are denoted hereafter as OM. Table 3 reports the differences in the equally weighted averages of all of the ratios for each stock group across the funds (i.e., Qs - OM). Comparing the results in Panels A and B, the buy/sell and share increase/decrease ratios are mostly consistent with respect to the sign of the difference. That is, the changes in the final portfolio allocations are consistent with the trading activity of funds. However, the proposed measures of share increase/decrease might provide more useful results in testing the window-dressing hypothesis because these ratios analyze the change of the portfolio image by considering the final portfolio weights that funds must report to investors.

With regard to size groups, funds tend to increase their portfolio allocations to Ibex_Small more intensively during the disclosure months than during the rest of the year. In contrast, funds increase their allocations to NoIbex_Small less intensively during the disclosure months than during the remaining periods.

However, the results are much more interesting when combining size and recent returns because some aggregate results for the size groups are a combination of the opposite patterns among the return subgroups. For instance, the analysis finds contrary and significant results in the high and low return quartiles of Ibex_Large. These results show that funds tend to increase their portfolio shares of return-winner large stocks (Ibex_LargeW) more in the reporting periods than in the other months. In contrast, funds tend to decrease their shares of these stocks more during the other periods than in the disclosure periods. However, the opposite occurs with return-loser large stocks (Ibex_LargeL); the share increase ratios are higher in the non-reporting months, and the share decrease ratios are higher in the disclosure months. Both ratios have statistically significant differences (Diff) at the $1 \%$ level. Furthermore, the finding related to the Ibex_LargeL stocks is the most robust result because the funds also show a clear intention to buy these stocks more actively in the non-reporting months (see the significant buy ratio in Panel A). This practice suggests that funds avoid well-known and large cap stocks with poor past return records in their mandatory reports. 
Table 3 Differences between the disclosure dates and the other months: Dec. 1999 through Dec. 2006. At the end of each quarter, this study sorts the stocks into two groups: those that belong to the Spanish benchmark Ibex35 (Ibex) and the remaining (Nolbex). Next, the procedure divides each group into large-cap stocks (Large) and small-cap stocks (Small). The Large subgroup represents approximately $60 \%$ of the total group's market capitalization. Additionally, the method sorts these stocks in relation to the previous 11-month cumulative returns. Then, this procedure obtains the top (W) and bottom (L) 11-month return quartiles within the four size subgroups. Panel A shows the equally weighted average of the trading activity ratios (Eqs. 6 and 7) across the funds for the disclosure months $(\mathrm{Qs})$ and the other months $(\mathrm{OM})$. Panel B reports the same structure for the portfolio weight ratios (Eqs. 8 and 9). (Diff) shows the difference between the values in Qs and OM for each measure. Finally, four performance quartiles in relation to the previous 11-month cumulative returns are obtained: Winner, Medium-Winner, Medium-Loser, and Loser

\begin{tabular}{|c|c|c|c|c|c|c|c|c|c|c|c|c|}
\hline & \multicolumn{6}{|c|}{ Panel A: Measures of trading activity } & \multicolumn{6}{|c|}{ Panel B: Measures of portfolio weights } \\
\hline & \multicolumn{3}{|c|}{ Sell ratio } & \multicolumn{3}{|c|}{ Buy ratio } & \multicolumn{3}{|c|}{ Share decrease ratio } & \multicolumn{3}{|c|}{ Share increase ratio } \\
\hline & Qs & $\mathrm{OM}$ & Diff & Qs & $\mathrm{OM}$ & Diff & Qs & $\mathrm{OM}$ & Diff & Qs & OM & Diff \\
\hline Ibex_Large & 0.80 & 0.80 & 0.00 & 0.76 & 0.82 & $-0.06^{*}$ & 2.04 & 2.04 & 0.00 & 2.02 & 2.09 & -0.07 \\
\hline Ibex_LargeW & 1.52 & 1.31 & 0.21 & 1.37 & 1.49 & -0.12 & 2.02 & 2.21 & $-0.19 *$ & 2.12 & 1.96 & $0.16^{*}$ \\
\hline Ibex_LargeL & 1.75 & 1.67 & 0.08 & 1.63 & 2.18 & $-0.55 * *$ & 2.29 & 1.93 & $0.36^{* *}$ & 2.22 & 2.46 & $-0.24 * *$ \\
\hline Ibex_Small & 1.30 & 1.30 & 0.00 & 1.26 & 1.23 & 0.03 & 0.91 & 0.90 & 0.01 & 0.95 & 0.90 & $0.05^{* *}$ \\
\hline Ibex_SmallW & 1.51 & 1.68 & $-0.17^{*}$ & 1.46 & 1.50 & -0.04 & 0.94 & 0.98 & -0.04 & 0.97 & 0.90 & $0.07 * *$ \\
\hline Ibex_SmallL & 1.51 & 1.43 & 0.08 & 1.58 & 1.47 & 0.11 & 0.82 & 0.79 & 0.03 & 0.78 & 0.88 & $-0.10 * *$ \\
\hline NoIbex_Large & 3.84 & 3.96 & -0.12 & 4.03 & 4.33 & -0.30 & 0.95 & 0.95 & 0.00 & 0.92 & 0.87 & 0.05 \\
\hline Nolbex_LargeW & 4.74 & 4.80 & -0.06 & 4.38 & 6.02 & $-1.64 * *$ & 1.05 & 1.21 & -0.16 & 0.95 & 0.98 & -0.03 \\
\hline NoIbex_LargeL & 4.03 & 3.99 & 0.04 & 5.18 & 5.71 & -0.53 & 0.85 & 0.70 & $0.15^{* *}$ & 0.90 & 0.91 & -0.01 \\
\hline NoIbex_Small & 3.11 & 3.02 & 0.09 & 2.78 & 2.92 & -0.14 & 0.60 & 0.61 & -0.01 & 0.56 & 0.62 & $-0.06^{*}$ \\
\hline NoIbex_SmallW & 4.69 & 3.69 & 1.00 & 3.10 & 3.59 & -0.49 & 0.74 & 0.79 & -0.05 & 0.63 & 0.71 & $-0.08^{*}$ \\
\hline NoIbex_SmallL & 4.13 & 3.64 & 0.49 & 2.88 & 3.33 & -0.45 & 0.53 & 0.52 & 0.01 & 0.48 & 0.58 & $-0.10 * *$ \\
\hline Winner & 1.42 & 1.50 & -0.08 & 1.32 & 1.42 & $-0.10^{*}$ & 0.98 & 1.05 & $-0.07 * *$ & 0.94 & 0.94 & 0.00 \\
\hline Medium-Winner & 1.06 & 1.04 & 0.02 & 0.96 & 1.03 & $-0.07 * *$ & 0.99 & 1.00 & -0.01 & 1.01 & 1.01 & 0.00 \\
\hline Medium-Loser & 1.07 & 1.04 & 0.03 & 1.03 & 1.02 & 0.01 & 0.99 & 0.97 & 0.02 & 1.06 & 0.96 & $0.10^{* *}$ \\
\hline Loser & 1.18 & 1.11 & 0.07 & 1.29 & 1.14 & $0.15 * *$ & 0.94 & 0.92 & 0.02 & 0.93 & 1.02 & $-0.09 * *$ \\
\hline
\end{tabular}

* $5 \%$ significant; ** $1 \%$ significant

The results for the Ibex_Small group are in line with those for the Ibex_Large group. Funds treat the extreme return-winners and losers differently. That is, managers tend to increase their shares of high-performance stocks (Ibex_SmallW) more in the reporting months than during the rest of the year, but the managers show the opposite behavior for return-loser stocks (Ibex_SmallL).

These findings regarding Ibex-35 stocks suggest that funds have quarter-end image strategies that differ from those undisclosed portfolios of the remaining months. This conclusion is especially relevant because these blue-chip stocks play a leading role in the portfolios of the sample according to Table 1 . The results indicate that during the reporting months, managers prefer large-cap and well-known stocks (i.e., Ibex-35 stocks) and have incentives to increase the disclosed portfolio weights of return-winners and decrease the weights of return-losers, especially those largest capitalization Ibex-35 stocks.

These results are consistent with the window-dressing hypothesis. That is, managers intend to improve the fund image by increasing the disclosed weights of well-known and return-winner stocks and decreasing the portfolio weights of well-known stocks with poor return records. 
The results for Nolbex stocks suggest that funds tend to increase the portfolio shares of the smallest stocks (NoIbex_Small), especially loser stocks, more actively in those months without portfolio reports. Although this study does not find a clear tendency toward selling and decreasing the portfolio shares of NoIbex stocks in the disclosure months, the results could loosely be in accordance with the window-dressing hypothesis.

The analysis of undisclosed portfolios let us conclude that Spanish domestic equity funds show intra-quarter trading missed using disclosed holdings. However, the differential trading that managers follow hardly compensate fees as we stated in section 2.2. Musto (1999) already pointed out that window dressing would involve higher transaction costs in equity funds than in other categories such as money market funds. Next section further investigates the effect of unobserved mutual fund trades on fund returns.

\subsection{Implications of Unobserved Mutual Fund Trades on Fund Performance}

One of the motivations that managers have to trade their portfolios differently in undisclosed periods is to benefit from the convex performance-flow relationship for mutual funds (e.g. Ippolito (1992) and Sirri and Tufano (1998), among others). Managers might try to improve the disclosed portfolio image to create the impression that the fund is performing relatively well to attract larger money inflows from investors (He et al. 2004; Lakonishok et al. 1991; Morey and O'Neal 2006; Musto 1999; Ng and Wang 2004; Ortiz et al. 2012), who mostly make their investment decisions based on recent performance records (Sirri and Tufano 1998). This attitude could lead to an important agency problem because fund management might be biased to total return instead of pursuing good performance. Being aware of investors' decision making process, managers' goal is attracting more assets under management to be rewarded accordingly. Then, any intra-quarter unobserved mutual fund trade should be aimed at total returns directly observed by investors. If investors are likely to focus on monthly mutual funds returns in making their investment decisions, it is necessary to check for the monthly mutual fund total returns of the most aggressive intra-period traders.

Panel data of monthly total fund returns are regressed against monthly turnover ratios to detect any significant relation between trading activity and performance. The first panel data regression considers all the funds included in the sample (6,894 observations); the results reject a significant relation between monthly returns and monthly turnover ratios (coefficient= 0.00205 with a $p$-value $=0.251$ ). We also run the same panel data but only considering those funds included in the first quartile of average monthly turnover. This analysis should further isolate the effect of the most aggressive mutual funds into their total monthly returns $(1,186$ observations). These results provide evidence of a negative although non-significant relation between intra-quarter trading activity and monthly total returns (coefficient $=-0.00129$ with a p-value $=0.345)^{9}$

Therefore, according to above results, the missing trades do not have a significant impact on monthly mutual fund returns, even for those funds with higher levels of monthly trading activity.

\footnotetext{
${ }^{9}$ We obtain Fama-MacBeth standard errors, White consistent standard errors, and OLS standard errors clustered by fund, by time, and by both fund and time. According to Petersen (2008), the comparison of these panel data standard errors leads us to accept the existence of a time effect in the panel data regression for the full sample. This effect may be controlled by using the correct confidence intervals based on the Fama-MacBeth and OLS standard errors clustered by time. However, the same procedure rejects any fund and time effect when the most aggressive intra-quarter funds are considered in the panel data regression. Detailed information regarding the standard error estimates is available on request.
} 
We carry out an additional analysis to try to disentangle the potential effect of unobserved mutual fund trading practices on funds' returns. A two-sample variance comparison test provides evidence that mutual fund returns are significantly less volatile in the non-reporting months $(\mathrm{sd}=4.665 \%)$ than in the remaining periods $(\mathrm{sd}=5.622 \%)$. In terms of return, a twosample mean comparison test finds that monthly returns are significantly higher in the nonreporting periods (mean $=1.348 \%$ ) than in the reporting periods (mean $=-0.523 \%$ ). Therefore, these findings support that the apparently different trading practice in the reporting periods seems to affect negatively to performance of equity funds. ${ }^{10}$

Related to unobserved trading is worth noting the confidential story recently addressed by Agarwal et al. (2013), which supports that managers may hide their most valuable information in portfolio reports. This confidential hypothesis is based on quarter-end portfolio holdings which are allowed to be disclosed with a delay up to 1 year. The confidential treatment by U.S. SEC relied on the argument that copycat competitors could mimic the disclosed strategies impeding fair competition.

This confidential behavior is restricted in the Spanish fund industry. Portfolio holdings file must be sent to CNMV with a maximum lag of 30 days since the quarter-end. But the nature of this confidential hypothesis still holds for our sample of undisclosed portfolios; managers would be motivated to sell those stocks with superior returns to avoid mimicking strategies from competitors before reporting.

Table 3 rejects a significant selling activity at the last month of the quarter of those stocks with the highest previous 11-month cumulative returns (winners). In fact, the results show that the portfolio allocation to these winners decrease significantly more in other periods than in the reporting months, which casts doubt on the significance of this confidential story in our sample.

If we extend this analysis to other stock characteristics corresponding to greater information asymmetry, Table 3 also rejects the existence of this confidential trading story in smaller stocks such as NoIbex_Small stocks. This lack of evidence may make sense in the Spanish fund industry because the confidential treatment by the market regulator such as in the U.S. market seems to be necessary to appropriately justify this behavior.

\subsection{Further Evidence of Mutual Fund Trading}

The conclusions drawn in previous section on unobserved mutual fund trades must be taken with caution in a so concentrated Spanish fund industry where variables such as fund size, age and recent returns could play an important role to drive equity fund trading. In this section we test whether these results about mutual fund trading are consistent across several subsets of funds with assorted characteristics that might imply different trading incentives.

Brown et al. (1996) provide empirical evidence that an agency problem creates incentives to add variance to the portfolios of smaller and younger equity funds as a consequence of the convex relationship between past returns and net money flows. According to Musto (1999), this agency problem might be also present in the analysis of window dressing hypothesis because smaller and younger funds might have important incentives to improve the portfolio image to get better investors' opinions about the fund and thereby gaining net money flows to

\footnotetext{
${ }^{10}$ Both hypotheses were tested at $95 \%$ confidence interval. The mean comparison test uses Welch's approximation to degrees of freedom due to the rejection of equal variance hypothesis. Detailed results of these tests are available upon request. Further studies should verify in much more detail the consequences of portfolio manipulation in terms of return and risk but this objective is beyond the goals of our paper.
} 
grow and survive. This hypothesis might be especially relevant in the very concentrated Spanish fund industry as a consequence of the universal banking model where a large number of small-sized funds compete against few large funds usually managed by large bank-owned companies. $^{11}$

We also extend the analysis to those funds with poor recent returns. These worse performers might also have incentives to avoid investors' suspicions of the quality of recent management which could finally result in net money outflows of the fund. The perception of investors interested in the explanatory factors of poor recent returns could be an important incentive for managers to improve the disclosed portfolio image to avoid the potential money outflows.

We follow the clustering approach of Musto (1999) to work with different subsets of funds. For each monthly trade we compute the fund i size in month $t$ minus the average fund size over that month. This relative size is standardized $s_{i t}$ minus the mean size and over the standard deviation of all size observations. Then, the standardized fund age $a_{i}$ is similarly obtained. Finally, for each monthly trade we obtain the past 3-month return for each fund i minus the average 3-month return of all funds over month t. This relative 3-month return is standardized $r_{i t}$ minus the mean return and over the standard deviation of all return observations. ${ }^{12}$ Table 4 repeats the same tests than Table 3 but clusters the difference estimates into six groups according to the standardized values. ${ }^{13}$

Similarly to Table 3, the most interesting results are again appreciated in Ibex-35 stocks. Panel A of Table 4 shows that the aggregate evidence of window dressing for these stocks previously reported in section 3.1 seems to be significantly driven by small equity funds. This finding supports the hypothesis of Musto (1999) of a fund-size agency problem in the fund trading around portfolio disclosures. The smallest equity funds increased significantly less the portfolio weights of Ibex stocks with poor returns (Ibex_LargeL and Ibex_SmallL) during disclosure months than in other periods, although this practice may be extended to all funds for Ibex-SmallL stocks. Small equity funds also increase significantly more the weights of return-winner Ibex_Small stocks (Ibex_SmallW) in disclosure months than in other periods. On the left side of Table 4, we find that the smallest equity funds decrease significantly less the portfolio weights of the largest Ibex stocks with better returns (Ibex_LargeW) in those reporting months than in other periods. Although Panel A of Table 4 does not report so clear results for NoIbex stocks, the findings suggest that the smallest funds tend to increase the weights of the smallest and loser stocks (NoIbex_SmallL) significantly more in those months without portfolio reports. In addition, the smallest funds also decrease significantly more the allocations to NoIbex_LargeL stocks in those reporting months.

These new results seem to verify that small equity funds aim to plan their trades around report dates to improve the quarterly portfolio image to grow and survive in the concentrated Spanish market, thereby supporting a fund-size agency problem in these fund trades in disguise.

\footnotetext{
${ }^{11}$ The ten largest out of the 102 Spanish fund companies existing in December 2006 managed more than $70 \%$ of the total assets of the Spanish fund industry. The average fund size in Spain was about 89 million $€$ while the average fund size in the European industry was about 160 million $€$ (Source: Inverco and European Fund and Asset Management Association, International Statistical Release 2006:Q4).

${ }^{12}$ Total fund assets and 3-month returns are officially provided by CNMV. The age of the funds is computed in days since the inception dates officially registered in the CNMV.

${ }^{13}$ According to section 3.1, the change of the portfolio image is better represented by the estimates of the portfolio weight ratios (Equations 8 and 9). Table 4 omits the estimates of the trading activity ratios (Equations 6 and 7) previously displayed in Table 3 for the sake of brevity but this information is available upon request.
} 


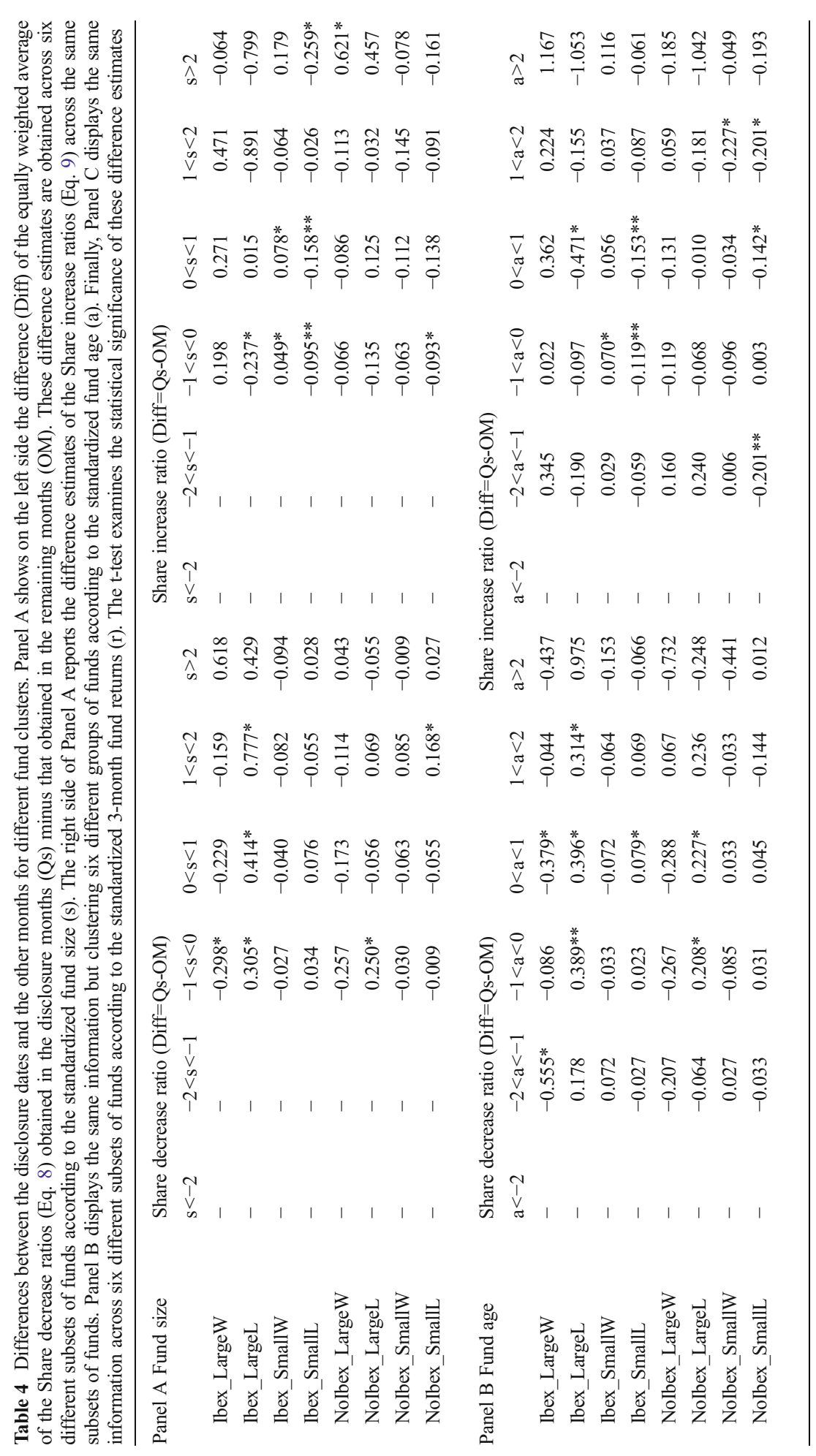




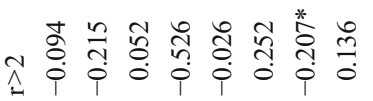

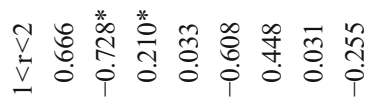

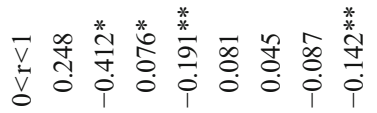

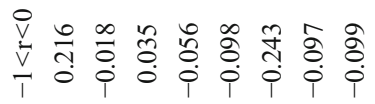

$\sum_{0} T$

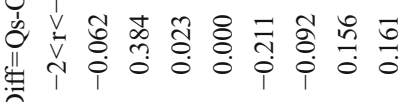

ê

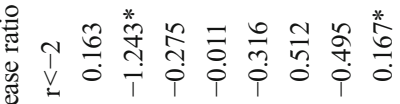

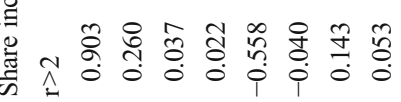

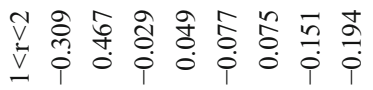

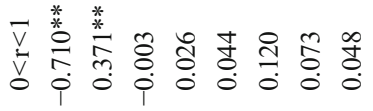

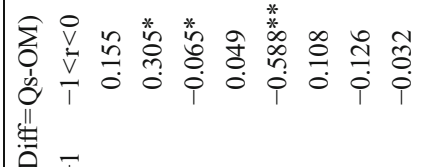

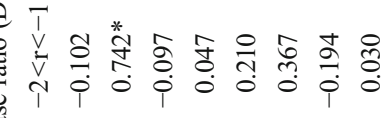

ॠ

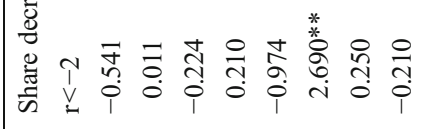

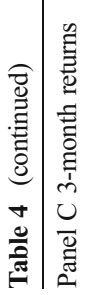

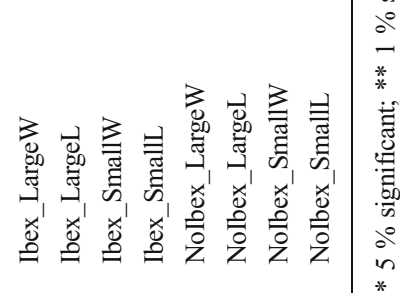


On the other hand, we cannot find a consistent fund-age agency problem to explain the trading patterns displayed by Panel B of Table 4. The lack of long return series could be an important incentive for investors to analyze the quarterly portfolios as a source of the recent performance. However, the empirical evidence of this hypothesis could be severely distorted by the existence in our sample of experienced and small funds managed by small-sized fund companies with more window dressing incentives than other younger and larger funds managed by large bank-owned companies with a robust sales force of mutual fund units. ${ }^{14}$

Finally, Panel C of Table 4 also questions the role of poor recent returns to explain unobserved trading strategies of Spanish equity funds. This lack of evidence could be explained because higher levels of stock substitution to improve the portfolio image of poor performers around portfolio reports should result in extra transaction costs which would push return records down even more. These additional costs would be an important problem for equity managers to plan investment decisions according to quarterly disclosure schedule. Furthermore, according to Musto (1999) the realized returns of equity funds should be much more informative than return records of money market funds, thereby questioning this fund-return agency problem in window dressing of fund categories different to money funds. ${ }^{15}$

\section{Fund Trading Strategies: Do Mutual Funds Benefit from the January Effect?}

Several studies analyze the different incentives and the consequences of portfolio manipulation on return patterns around reporting dates (Carhart et al. 2002; Gallagher et al. 2009; Bernhardt and Davies 2005). In particular, past research has shown a special interest in the role of this institutional practice in some well-known market anomalies, such as the January effect (Haugen and Lakonishok 1988; Ackert and Athanassakos 2000; Ng and Wang 2004; Sias and Starks 1997; Lee et al. 1998). This institutional trading may complement the extended hypothesis of tax-motivated trades by individuals as the main explanation for the January effect since the study of Dyl (1977). However, the role of Spanish institutional investors is questionable, given that domestic equity funds own a low percentage of the stock market (see Panel B of Table 1).

This paper provides further insights into the role of fund managers in the January effect. That is, this section details fund trading in the first quarter to better understand those trades causing the highest turnover ratio in the year, $42.12 \%$ in January (see Table 2). This result might initially reflect the potential participation of mutual funds in the turn-of-the-year effect.

As the nature of this analysis only requires trading activities, Table 5 only reports sell and buy ratios (Eqs. 6 and 7). Table 5 reveals that in January, managers focus their trading activities on Nolbex stocks with a clear intention to purchase these stocks. The buy ratio is significantly higher than the sell ratio for these stocks and their extreme return subgroups. These differences are significant at the $1 \%$ and $5 \%$

\footnotetext{
${ }_{15}^{14}$ Descriptive statistics of the market concentration of the sample are available upon request.

${ }^{15} \mathrm{We}$ also run panel data regressions to test the robustness of the interaction between specific fund characteristics and portfolio weight ratios (Equations 8 and 9). According to Petersen (2008), we identify the correlations between the residuals across funds by comparing the standard errors obtained via the different panel data methods. The results are consistent with the evidence reported by Table 4 . Detailed statistics are available upon request.
} 
Table 5 Investment activity in the first quarter: Dec. 1999 through Dec. 2006. This table reports the equally weighted average of the buy and sell measures (Eqs. 6 and 7) across the funds during the first quarter of the year for the different stock groups. The t-test examines the equality of means between the buy and sell ratios (Diff $(B, S))$

\begin{tabular}{|c|c|c|c|c|c|c|c|c|c|}
\hline & \multicolumn{3}{|c|}{ January } & \multicolumn{3}{|c|}{ February } & \multicolumn{3}{|c|}{ March } \\
\hline & Buy & Sell & $\operatorname{Diff}(B, S)$ & Buy & Sell & Diff $(B, S)$ & Buy & Sell & $\operatorname{Diff}(B, S)$ \\
\hline Ibex_Large & 0.83 & 0.81 & 0.02 & 0.86 & 0.76 & 0.10 & 0.79 & 0.88 & -0.09 \\
\hline Ibex_LargeW & 1.94 & 1.62 & 0.31 & 1.03 & 1.38 & $-0.35^{*}$ & 1.35 & 1.66 & -0.31 \\
\hline Ibex_LargeL & 1.31 & 1.72 & -0.41 & 1.34 & 1.26 & 0.08 & 1.57 & 1.55 & 0.03 \\
\hline Ibex_Small & 1.14 & 1.27 & $-0.12 * *$ & 1.26 & 1.31 & -0.05 & 1.22 & 1.30 & -0.08 \\
\hline Ibex_SmallW & 1.41 & 1.61 & -0.20 & 1.16 & 2.04 & $-0.88^{* *}$ & 1.40 & 1.82 & $-0.42^{* *}$ \\
\hline Ibex_SmallL & 1.53 & 1.28 & 0.25 & 1.54 & 1.61 & -0.07 & 1.47 & 1.67 & -0.20 \\
\hline NoIbex_Large & 6.28 & 3.43 & $2.85^{* *}$ & 2.14 & 5.88 & $-3.74 * *$ & 2.41 & 3.17 & -0.76 \\
\hline NoIbex_LargeW & 7.32 & 4.06 & $3.26^{*}$ & 3.46 & 9.71 & $-6.25^{* *}$ & 3.93 & 4.43 & -0.50 \\
\hline NoIbex_LargeL & 9.35 & 3.48 & $5.87 * *$ & 3.04 & 4.97 & -1.94 & 4.29 & 3.27 & 1.02 \\
\hline NoIbex_Small & 4.76 & 2.55 & $2.21^{*}$ & 3.27 & 2.52 & 0.76 & 2.38 & 2.94 & -0.56 \\
\hline NoIbex_SmallW & 5.62 & 2.54 & $3.08^{*}$ & 3.48 & 3.28 & 0.20 & 2.55 & 4.76 & -2.20 \\
\hline NoIbex_SmallL & 3.70 & 3.43 & 0.27 & 3.64 & 3.33 & 0.32 & 3.25 & 3.12 & 0.12 \\
\hline
\end{tabular}

* $5 \%$ significant; ** $1 \%$ significant

levels, except for NoIbex_SmallL. These findings might be related to the cause of the January effect in Spanish small-cap stocks (Ortiz et al. 2010).

We also obtain the $€$-value of the trades of our fund sample in January by comparing the portfolios at the end of December and January (Eqs. 1 and 2). This analysis shows that the trades of our sample are on average $2.67 \%(1.11 \%)$ of the overall Spanish market trading of NoIbex (Ibex35) stocks in January. ${ }^{16}$ Spanish domestic equity funds do actively trade smallcap stocks in January to take advantage of the subsequent rise in prices but cannot produce any price pressure to be causing the return anomaly.

\section{Conclusion}

Recent research analyzes mutual fund trading around mandatory portfolio reports. However, few studies use holdings data reported more frequently than on a quarterly basis. This frequency could severely bias their conclusions because a relevant percentage of trades are missing when quarterly holdings are used, thereby strengthening the use of monthly data for appropriate tests of mutual fund trading. This paper examines a unique and official database of monthly undisclosed portfolios to explore equity fund trading around portfolio disclosures. In fact, the use of quarterly portfolios missed $38 \%$ of the trading revealed using monthly portfolios. However, the intra-quarter round trip trades do not significantly affect fund returns, even for those funds with higher levels of monthly activity.

\footnotetext{
${ }^{16}$ The sum of $\mathrm{C}_{\text {January }}^{+}$and $\mathrm{C}_{\text {January }}^{-}$is a conservative measure of the trading volume in January because it omits the intra-January round-trip trades. However, according to Elton et al. (2010) this intra-month bias is expected to be small because of the high transaction costs assumed by these trades. Total Spanish market trading has been obtained from the Official Bulletins of the Spanish Stock Market. Detailed figures are omitted for the sake of brevity.
} 
Trading ratios existing in the literature and our new portfolio measure aim to detect equity funds trading activity around the quarterly portfolio reports. These patterns depend on both the size and recent performance records of the stocks. Our new approach captures the general trading effect on the stock weights, which better show a portfolio's image.

The results for the large-cap and well-known Ibex-35 stocks suggest that funds tend to rebalance their portfolios to increase the weights of the return-winner stocks and to decrease the weights of the poor-return stocks in the disclosure months. Interestingly, non-disclosure months show the opposite trend. These results are especially relevant because Ibex stocks play a leading role in the fund portfolio holdings. However, the results for Nolbex stocks suggest that funds tend to increase the weights of these small-cap stocks more actively in the nondisclosure months. Thus, funds might trade in order to show well-known stocks in their quarterly reports.

Our results also reject any intra-quarter confidential trading story which is based on those portfolio holdings allowed by the U.S. SEC to be disclosed with a certain delay. This lack of evidence makes sense in Spain because this confidential treatment is not allowed by the Spanish regulator.

The paper finds evidence of a fund-size agency problem to explain fund unobserved trading in the Spanish concentrated market. Small equity funds are involved in intra-quarter trading, but no significant results are found in relation with the age of the fund and the past fund returns.

Our database allows the analysis of the influence of January effect on mutual fund trading. During the first quarter of the year, funds mainly concentrate on trading NoIbex stocks. The results indicate that funds actively participate in the January effect, especially by purchasing small-cap stocks. However, domestic equity funds own a residual capitalization percentage of Spanish listed companies. This finding suggests that funds might take advantage of the January effect rather than causing this return anomaly.

Acknowledgments The authors thank the UCEIF Foundation, research project ECO2009-12819-C0302 of the Spanish Department of Science, and research project 268-159 of the University of Zaragoza for their financial support. We appreciate insightful comments from David Musto (editor) and the anonymous referee, Manuel Armada, Alexander Kempf, Van Thi Tuong Nguyen, Auke Plantinga, José Luis Sarto, and the participants of the EFMA 2011 annual meeting. Any possible errors in this article are the exclusive responsibility of the authors.

\section{References}

Ackert LF, Athanassakos G (2000) Institutional investors, analyst following, and the january anomaly. J Bus Finance Account 27(3-4):469-485

Agarwal V, Jiang W, Tang Y, Yang B (2013) Uncovering hedge fund skill from the portfolio holdings they hide. J Finance 68(2):739-783

Bernhardt D, Davies RJ (2005) Painting the tape: aggregate evidence. Econ Letters 89(3):306-311

Brown KC, Harlow WV, Starks LT (1996) Of tournaments and temptations: an analysis of managerial incentives in the mutual fund industry. J Finance 51(1):85-110

Carhart MM, Kaniel R, Musto D, Reed AV (2002) Leaning for the tape: evidence of gaming behavior in equity mutual funds. J Finance 57(2):661-693

Dyl EA (1977) Capital gains taxation and year-end stock market behavior. J Finance 32(1):165-175

Elton EJ, Gruber MJ, Blake CR (2012) An examination of mutual fund timing ability using monthly holding data. Rev Finance 16(3):619-645 
Elton EJ, Gruber MJ, Blake CR, Krasny Y, Ozelge SO (2010) The effect of holdings data frequency on conclusions about mutual fund behavior. J Banking Financ 34:912-922

Gallagher DR, Gardner P, Swan PL (2009) Portfolio pumping: an examination of investment manager quarterend trading and impact on performance. Pacific-Basin Financ J 17:1-27

Haugen RA, Lakonishok J (1988) The incredible january effect: the stock market's unsolved mystery. DowJones-Irwin, Homewood, III

He J, Ng L, Wang Q (2004) Quarterly trading patterns of financial institutions. J Bus 77(3):493-509

Ippolito RA (1992) Consumer reaction to measures of poor quality: evidence from the mutual fund industry. J Law Econ 35(1):45-70

Kacperczyk M, Sialm C, Zheng L (2008) Unobserved actions of mutual funds. Rev Financ Stud 21(6):23792416

Kotomin V, Winters DB (2006) Quarter-End effects in banks: preferred habitat or window dressing. J Financ Serv Res 29(1):61-82

Lakonishok J, Shleifer A, Thaler R, Vishny R (1991) Window dressing by pension fund managers. Amer Econ Rev 81(2):227-231

Lee C, Porter DC, Weaver DG (1998) Indirect tests of the haugen-Lakonishok small-firm/january effect hypotheses: window dressing versus performance hedging. Financ Rev 33(2):177-194

Liao T-L, Huang C-J, Wu C-Y (2010) Do fund managers herd to counter investor sentiment? J Bus Res 64(2): 207-212

Meier I, Schaumburg E (2006) Do funds window dress? Evidence for U.S. domestic equity mutual funds. Northwestern University

Morey MR, O’Neal ES (2006) Window dressing in bond mutual funds. J Financ Res 29(3):325-347

Musto D (1997) Portfolio disclosures and year-end price shifts. J Financ 52(4):1563-1588

Musto D (1999) Investment decisions depend on portfolio disclosures. J Financ 54(3):935-952

$\mathrm{Ng}$ L, Wang Q (2004) Institutional trading and the turn-of-the-year effect. J Financ Econ 74:343-366

Ortiz C, Ramírez G, Vicente LA (2010) Quarterly return patterns in the spanish stock market. Appl Financ Econ 20(23):1829-1838

Ortiz C, Sarto JL, Vicente LA (2012) Portfolios in disguise? window dressing in bond fund holdings. J Bank Financ 36:418-427

Petersen MA (2008) Estimating standard errors in finance panel data sets: comparing approaches. Rev Financ Stud 22:435-480

Sias RW, Starks LT (1997) Institutions and individuals at the turn-of-the-year. J Finance 52(4):1543-1562

Sirri ER, Tufano P (1998) Costly search and mutual fund flows. J Financ 53(5):1589-1622 